\title{
Avaliação da atividade antifúngica dos óleos essencias de Lippia alba (Mill.) N. E. Brown (Verbenaceae) e Cymbopogon citratus (D.C.) Stapf (Poaceae)
}

\author{
Evaluation of antifungal activity of essential oils of Lippia alba (Mill.) N. E. \\ Brown (Verbenaceae) e Cymbopogon citratus (D.C.) Stapf (Poaceae)
}

\author{
Lúcia Elaine Ranieri Cortez ${ }^{*}$ \\ Mirian Ueda Yamaguchi** \\ Diógenes Aparício Garcia Cortez *** \\ Danielle Cristina Sampaio Pesco ${ }^{* * * *}$
}

\begin{abstract}
Resumo
A utilização de plantas medicinais é bastante difundida em todo o mundo inclusive no Brasil, onde há grande variedade de espécies e extensa tradição em sua utilização. Objetivou-se com esse estudo avaliar a atividade antifúngica dos óleos essenciais de Lippia alba (Mill.) N. E. Brown (Verbenaceae), e Cymbopogon citratus (DC) Stapf separadamente, bem como a mistura destes. A obtenção dos óleos essenciais foi realizada a partir de folhas secas, empregando-se a técnica de destilação por arraste a vapor no aparelho de Clevenger por um período de 3 horas, A atividade antifúngica foi determinada pela Concentração Inibitória Mínima (CIM), obtida por técnicas de microdiluição em caldo e Concentração Fungicida Mínima (CFM), frente às cepas de Candida albicans (ATCC 10231), Candida tropicalis (ATCC 28707) e Candida parapsilosis (ATCC 22019). Através dos resultados obtidos, verificou-se que os óleos essenciais de Lippia alba e de Cymbopogon citratus apresentaram atividade antifúngica frente a todas as cepas de Candida, sendo que uma melhor atividade foi observada no óleo essencial de Cymbopogon citratus. É visto também que a mistura dos óleos essenciais não potencializou a atividade antifúngica para os microrganismos testados. Pesquisas futuras serão necessárias para avaliar a interação entre os óleos, bem como determinar quais substâncias específicas são responsáveis por essa atividade.
\end{abstract}

Palavras chave: Óleo Essencial. Lippia Alba. Cymbopogon Citratus. Atividade Antifúngica.

\begin{abstract}
The use of medicinal plants is widespread throughout the world including Brazil, where there is a great variety of species and extensive tradition in its use. The objective of this study was to evaluate the antifungal activity of the following essential oils; Lippia alba (Mill.) N.E. Brown (Verbenaceae), and Cymbopogon citratus (DC) Stapf individually as well as its mixture. The extraction of these essential oils was done with dried leaves, using the technique of distillation by steam suction on the Clevenger apparatus for a period of 3 hours. Antifungal activity was determined by Minimum Inhibitory Concentration (MIC), obtained by micro-dilution techniques and Minimum Fungicidal Concentration (MFC), front strains of Candida albicans (ATCC 10231), Candida tropicalis (ATCC 28707) and Candida parapsilosis (ATCC 22019).From the results obtained, it was found that the essential oils Lippia alba and Cymbopogon citratus showed antifungal activity against all strains of Candida, being that better activity was observed by the essential oil of Cymbopogon citratus. It was also seen that the blend of the essential oils did not strengthen the antifungal activity against the microorganisms that were tested. However, this study was only the first step, requiring new research to assess the interaction between the oils, as well as determine which specific substances are responsible for this activity.
\end{abstract}

Keywords: Essential Oil. Lippia Alba. Cymbopogon Citratus. Antifungal Activity.

DOI: 10.15343/0104-7809.20153904433440

* Centro Universitário Cesumar - UniCesumar - Maringá/ PR - Brasil. E-mail: lercortez@pop.com.br

** Centro Universitário Cesumar - UniCesumar - Maringá/ PR - Brasil. E-mail: mirianueda@gmail.com

*** Centro Universitário Cesumar - UniCesumar - Maringá/ PR - Brasil. E-mail: dagcortez@uem.br

**** Centro Universitário Cesumar - UniCesumar - Maringá/ PR - Brasil. E-mail: pescomineli@hotmail.com

Os autores declaram não haver conflitos de interesse. 


\section{INTRODUÇÃO}

Uma das maiores diversidades vegetais do mundo encontra-se no Brasil, bem como inúmeras experiências vinculadas ao conhecimento popular das plantas medicinais e tecnologias que correlacionam o saber popular e científico'.

A busca por plantas com potencial terapêutico é uma opção importante. Segundo Santos et $\mathrm{al}^{2}$, na medicina popular as plantas são utilizadas concomitantemente ao uso de medicamentos sintéticos, posto que estes últimos são muitas vezes considerados mais caros. Dessa forma, é crescente a procura por plantas medicinais e aromáticas em diversos países, devido à tendência dos consumidores em utilizarem, preferencialmente, produtos farmacêuticos ou alimentícios de origem natural. Assim, tecnologias naturais de conservação vêm se tornando cada vez mais importantes em indústrias de alimentos e os óleos essenciais constituem alternativas à obtenção de produtos microbiologicamente seguros ${ }^{3}$.

As plantas medicinais aromáticas apresentam em sua composição óleos essenciais. Estes são originados do metabolismo secundário das plantas e possuem composição química complexa, destacando-se a presença de terpenos e fenilpropanóides ${ }^{4}$. Esses óleos são encontrados em diversos órgãos vegetais, exercendo funções importantes para a sobrevivência do vegetal, particularmente, na defesa contra microrganismos ${ }^{4,5}$.

Tem sido demonstrada a eficiência dos óleos essenciais de um grande número de espécies botânicas em promover a inibição do desenvolvimento de fungos ${ }^{6}$. Os óleos essenciais como os de Cymbopogon martinii (palmarosa), Ocimum basilicum (manjericão) e Thymus vulgaris (tomiIho), por exemplo, apresentam atividade frente a espécies bacterianas e fúngicas, incluindo a $C$. albicans ${ }^{7}$. Entre outras espécies botânicas cujo óleo essencial pode apresentar efeito antifúngico incluem-se a erva cidreira (Lippia alba) e o Capím-limão (Cymbopogon citratus) ${ }^{8,9}$.

A espécie Lippia alba (Mill.) N. E. Brown (Verbenaceae), conhecida popularmente como erva cidreira, é amplamente distribuída em todo o território brasileiro e é utilizada na medicina popular como analgésica, febrífuga, antiinflamatória, antigripal e nas afecções hepáticas ${ }^{10}$. É uma planta bastante utilizada pela ampla variabilidade química de compostos, bem como, os óleos essenciais, sendo estas substâncias responsáveis por suas várias utilizações na medicina popular e na fitoterapia, com propriedades antiinflamatórias e antissépticas ${ }^{11}$, além de propriedades antibacterianas e antifúngicas ${ }^{8}$, e para distúrbios estomacais, sedativa, e infecções das vias respiratórias ${ }^{12}$.

A composição do óleo essencial da erva cidreira apresenta alta variação, o que sugere um agrupamento dos genótipos em quimiotipos, separados pelos seus elementos mais abundantes, como o quimiotipo I (citral e mirceno), o quimiotipo II (citral e limoneno) e o quimiotipo III (carvona e limoneno) ${ }^{8}$. Dentre os componentes do óleo essencial de $L$. alba, o linalol tem se destacado pelo seu expressivo rendimento na planta, por sua ampla utilização nas indústrias de aromatizantes, cosméticos e perfumes ${ }^{11}$.

A espécie Cymbopogon citratus (DC) Stapf, popularmente conhecida como capim-limão, é originária da Índia e encontra-se difundida em vários países e aclimatada nas regiões tropicais do Brasil. Das folhas secas também pode ser extraído o óleo essencial e ensaios farmacológicos realizados em animais, em adição às análises microbiológicas, evidenciam que os principais efeitos terapêuticos do capim limão estão relacionados com as atividades estomacais, analgésica, sedativa e antimicrobiana ${ }^{13}$, utilizada popularmente para flatulência, além de antiespasmódico de tecidos uterinos e intestinais, diaforético, antitérmico, diurético, antialérgico ${ }^{9}$.

O maior emprego do óleo essencial tem sido na indústria farmacêutica, servindo de material de partida para síntese de importantes compostos como iononas, metil-iononas e vitaminas $\mathrm{A}^{14}$.

O óleo essencial extraído de C. citratus tem como principal componente o citral composto pela mistura dos isômeros geranial e neral (65-80\%), além de limoneno, citronelal, 
mirceno e geraniol. As atividades antimicrobiana e antifúngica dos óleos essenciais de $C$. citratus foram atribuídas ao citral. No entanto, o mirceno não apresentou atividade antimicrobiana, mas, quando associado ao citral potencializou seu efeito ${ }^{9}$.

Nos últimos anos tem-se observado um aumento na incidência das infecções sistêmicas graves por fungos oportunistas devido à resistência destes frente frentes às classes atuais de antifúngicos, o que está correlacionado com o uso indiscriminado dos mesmos. Outrossim, os antifúngicos comumente usados causam efeitos adversos aos pacientes, que incluem hipersensibilidade, reações alérgicas e imunossupressão ${ }^{15}$.

Entre as espécies fúngicas que exigem atenção, encontra-se o gênero Candida spp que é responsável por cerca de $80 \%$ das infecções fúngicas no ambiente hospitalar e constitui causa relevante de infecções de corrente sanguínea. Espécies não-albicans são responsáveis por pelo menos 50\% das infecções invasivas por Candida spp, apresentando peculiaridades de história natural e sensibilidade a antifúngicos. A mortalidade geral por de fungemias por Candida sp é da ordem de 40 a $60 \%$ 16, 17, 18 .

Devido ao fato dos antifúngicos promoverem efeitos tóxicos, tem-se buscado uma alternativa mais eficiente e menos tóxica para o tratamento das infecções fúngicas por meio de produtos de origem vegetal, e o conhecimento de uma possível atividade antifúngica dos óleos essenciais dessas plantas são de muita importância, pois abre possibilidades para se estudar futuros medicamentos antifúngicos de origem natural.

Diante do que foi exposto, o objetivo deste trabalho foi avaliar a atividade antifúngica dos óleos essenciais das plantas Lippia alba (Mill.) N. E. Brown (Verbenaceae) e Cymbopogon citratus (D.C.) Stapf (Poaceae) separadamente, bem como da mistura de ambos.

\section{MATERIAL E MÉTODOS}

\section{Material vegetal}

Foram utilizadas folhas de Lippia alba (erva cidreira brasileira) e Cymbopogon citratus (capim limão) colhidas no mês de maio de 2014, no período da manhã, cultivadas em canteiros experimentais no campus-sede do UniCesumar, em Maringá. A cidade está localizada a 554 $\mathrm{m}$ acima do nível do mar, e suas coordenadas

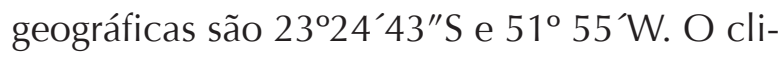
ma, pela classificação de Köeppen ${ }^{19}$, é do tipo $\mathrm{Cfa}(\mathrm{h})$ : clima subtropical mesotérmico, com verões chuvosos e geadas pouco frequentes. Foram selecionadas as plantas mais sadias e submetidas a secagem em temperatura ambiente, à sombra por um período de 10 dias para posterior extração de óleo essencial.

\section{Extração do óleo essencial}

A extração do óleo essencial das folhas foi realizada no laboratório do UniCesumar, pelo processo de destilação por arraste a vapor, no aparelho de Clevenger ${ }^{20}$, utilizando-se 100 gramas de folhas secas para $1000 \mathrm{~mL}$ de água destilada. O tempo de extração foi de 3 horas. Após este período, os óleos essenciais foram armazenados em frascos âmbar, na geladeira até o momento de sua utilização. A atividade antifúngica foi realizada separadamente para cada óleo, assim como a mistura dos mesmos em igual volume (1:1).

\section{Determinação da atividade antifúngica}

A técnica de microdiluição em caldo para a determinação da concentração inibitória mínima (CIM) foi realizada em microplacas estéreis de 96 cavidades (INLAB) com fundo em forma de " $U$ ". Inicialmente todos os poços da microplaca foram preenchidos com $100 \mu \mathrm{L}$ de caldo Saubouraud Dextrose. As amostras dos diferentes óleos essenciais de Lippia alba, Cymbopogon citratus e mistura de ambos, foram preparados na concentração de 2000 mg/mL empregando-se sulfóxido de dimetila (DMSO) a $10 \%$, que foram depositadas na primeira coluna da microplaca. Em seguida alíquotas de $100 \mu \mathrm{L}$ do conteúdo de cada orifício da coluna 1 foi transferida para os orifícios da coluna 2 e, após homogeneização, transferido o mesmo volume para a coluna 3. Este procedimento foi repetido até a coluna 12 e desprezado após homogeneização o excesso da diluição, obtendo-se, assim, concentrações decrescentes dos óleos essenciais 
$(1,0 \mathrm{mg} / \mathrm{mL}$ - coluna $1 ; 0,500 \mathrm{mg} / \mathrm{mL}$ - coluna 2; 0,250 mg/mL - coluna 3 e assim por diante).

Os inóculos microbianos com a concentração de 1,5 x $10^{6}$ microrganismos $/ \mathrm{mL}$, equivalente a densidade de McFarland ( $\left.10^{6} \mathrm{UFC} / \mathrm{mL}\right)$, foram diluídos 1/10 em solução salina estéril $(0,9 \%)$ e, desta diluição, um volume de $100 \mu \mathrm{L}$, foi depositado em todos os orifícios da coluna 1 nados para os testes de controle do experimento.

Os orifícios da linha $G$, foram reservados para o controle positivo, com caldo Sauboraud Dextrose (CSD) e inóculo microbiano. Os 4 orifícios da linha $\mathrm{H}$ receberam apenas caldo Saubouraud Dextrose para a verificação da esterilidade da placa e outros 4 orifícios foram utilizados para controle negativo do DMSO estéril a $10 \%$.

As microplacas foram incubadas em estufa bacteriológica a $37^{\circ} \mathrm{C}$ por 24 horas. Após esta incubação a presença de uma turvação nos orifícios foi interpretada como prova negativa do efeito inibitório do óleo essencial, enquanto a ausência da turvação foi considerada prova positiva da ação inibitória do óleo essencial.

Para a determinação da concentração fungicida mínima (CFM), transferiu-se $10 \mu \mathrm{L}$ dos PR (2014), sobre cepas de leveduras do gênero Candida.
Em relação a C. albicans, os dois óleos essenciais, bem como a mistura destes, apresentaram os mesmos valores de concentração de inibição mínima, que foram de 0,125 mg/mL. Quanto a Candida tropicalis a concentração de inibição mínima foi de $0,250 \mathrm{mg} / \mathrm{mL}$ do óleo essencial de Lippia alba, bem como a mistura poços das placas, com o auxílio de micropipetadores, para regiões determinadas de placa de petri contendo Agar Sabouraud Dextrose, e esta incubada por 24 horas a $37^{\circ} \mathrm{C}$. A região em que não houve crescimento fúngico é indicada como a menor concentração do óleo a ter ação fungicida ${ }^{21}$. Os óleos essenciais foram testados frente às cepas de Candida albicans ATCC 10231, Candida tropicalis ATCC 28707 e Candida parapsilosis ATCC 22019, e o experimento foi realizado em duplicata.

\section{RESULTADOS}

Em relação ao rendimento do óleo essencial obtido das espécies de erva cidreira, estas apresentaram um rendimento de $0,61 \%$ e $2,72 \%$, sendo estes da planta Lippia alba e Cymbopogon citratus respectivamente. Apesar de ambas serem referendadas popularmente como erva cidreira, são espécies diferentes e o rendimento de óleo essencial obtido foi variável. Em relação à atividade antifúngica dos óleos essenciais, a Tabela 1 apresenta os valores de concentração inibitória mínima (CIM), sobre as cepas de Candidas albicans, C. tropicalis e C. parapsilosis, para os óleos essenciais separadamente e a mistura de ambos em igual volume.

Tabela 1. Concentração Inibitória Mínima (CIM) de óleos essenciais de plantas cultivadas em Maringá -

\begin{tabular}{lccc}
\hline Cepas & Lippia alba $(\mathbf{m g} / \mathbf{m L})$ & Cymbopogon citratus $(\mathbf{m g} / \mathbf{m L})$ & Mistura dos óleos $(\mathbf{m g} / \mathbf{m L})$ \\
\hline $\begin{array}{l}\text { Candida albicans } \\
\text { ATC 10231 }\end{array}$ & 0,125 & 0,125 & 0,125 \\
$\begin{array}{l}\text { Candida tropicalis } \\
\text { ATCC 28707 }\end{array}$ & 0,250 & 0,125 & 0,250 \\
$\begin{array}{l}\text { Candida parapsilosis } \\
\text { ATCC 22019 }\end{array}$ & 0,500 & 0,125 & 0,250 \\
\hline
\end{tabular}

dos óleos, e de 0,125 mg/mL do óleo essencial de Cymbopogon citratus. Resultados maiores foram obtidos para Candida parapsilosis do óleo essencial de Lippia alba $(0,500 \mathrm{mg} / \mathrm{mL}), 0,125$ $\mathrm{mg} / \mathrm{mL}$ do óleo essencial de Cymbopogon citratus, e um valor intermediário de 0,250 mg/mL, quando avaliada a mistura dos óleos essenciais. 
Tabela 2. Concentração Fungicida Mínima (CFM) de óleos essenciais plantas cultivadas em Maringá - PR (2014), sobre cepas de fungos.

\begin{tabular}{lccc}
\hline Cepas & Lippia alba $(\mathbf{m g} / \mathbf{m L})$ & Cymbopogon citratus $(\mathbf{m g} / \mathbf{m L})$ & Mistura dos óleos $(\mathbf{m g} / \mathbf{m L})$ \\
\hline $\begin{array}{l}\text { Candida albicans } \\
\text { ATC 10231 }\end{array}$ & 1,0 & 0,500 & 1,0 \\
$\begin{array}{l}\text { Candida tropicalis } \\
\text { ATCC 28707 }\end{array}$ & 1,0 & 0,500 & 1,0 \\
$\begin{array}{l}\text { Candida paraplisosis } \\
\text { ATCC 22019 }\end{array}$ & 1,0 & 0,500 & 1,0 \\
\hline
\end{tabular}

Pode-se observar na Tabela 2, e Figuras 1, 2, e 3, atividade antifúngica mais efetiva do óleo de Cymbopogon citratus em relação à Lippia

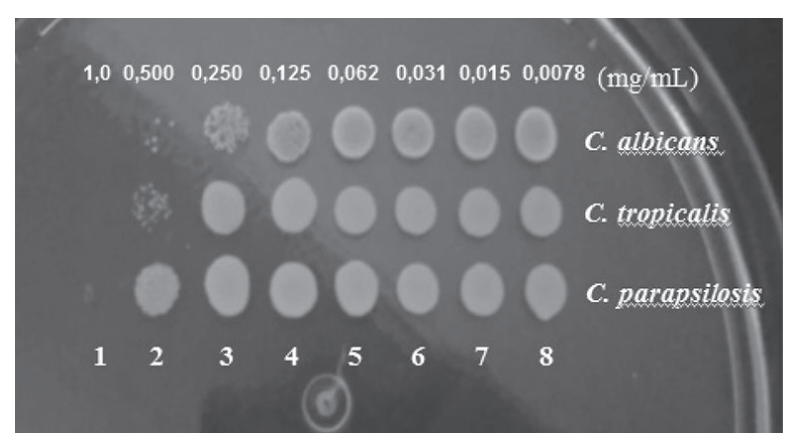

Figura 1. Atividade antifúngica (CFM) do óleo essencial de Lippia alba cultivada em Maringá - PR (2014) na concentração de $1,0 \mathrm{mg} / \mathrm{mL}$ a 0,0078 $\mathrm{mg} / \mathrm{mL}$, para as cepas de C. albicans, C. tropicalis e C. parapsilosis.

Não houve diferença entre a atividade antifúngica de Lippia alba e a mistura de óleos, visto que a concentração fungicida mínina foi de $1,0 \mathrm{mg} / \mathrm{mL}$ frente as três cepas, ou seja, é necessário o dobro da concentração deste óleo para se obter a atividade fungicida. É visto, portanto, que o óleo essencial de Cymbopogon citratus é mais ativo do que o óleo essencial de Lippia alba, bem como a mistura dos óleos em igual volume.

É possível observar nas Figuras 1 e 2, a ausência total de crescimento dos fungos (C. albicans, C. tropicalis e C. parapsilosis) na presença do óleo essencial de Lippia alba, bem como da misturas dos óleos na concentração de $1,0 \mathrm{mg} / \mathrm{mL}$, o que comprova a atividade alba, bem como a mistura destes, frente as três cepas testadas, onde a concentração fungicida mínima foi de $0,500 \mathrm{mg} / \mathrm{mL}$.

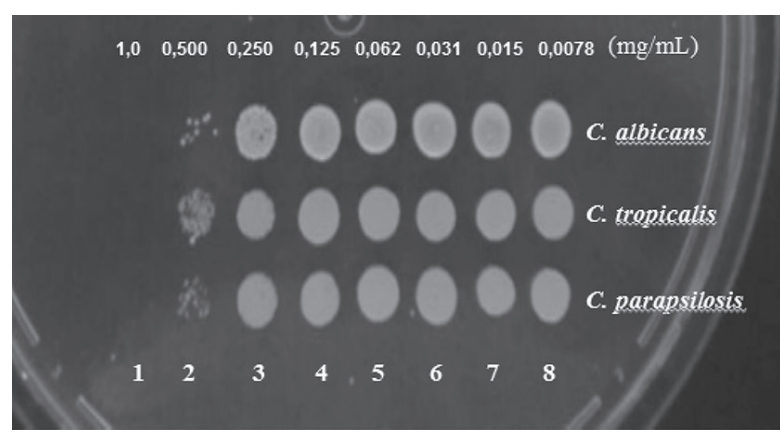

Figura 2. Atividade antifúngica (CFM) da mistura dos óleos essenciais das plantas cultivadas em Maringá - PR (2014) na concentração de 1,0 mg/ $\mathrm{mL}$ a $0,0078 \mathrm{mg} / \mathrm{mL}$, para as cepas de C. albicans, C. tropicalis e C. parapsilosis.

antifúngica dos mesmos nesta concentração. As figuras 1 e 2 permitem também observar que para a concentração $0,500 \mathrm{mg} / \mathrm{dL}$ houve crescimento menos intenso das espécies de candida, exceto para a C. parapsilosis na presença do óleo essencial de Lippia alba.

Na Figura 3, observa-se a atividade antifúngica na concentração de $0,500 \mathrm{mg} / \mathrm{mL}$ do óleo essencial de Cymbopogon citratus, o qual promoveu a ausência total de crescimento dos fungos (C. albicans, C. tropicalis e C. parapsilosis). Pode-se observar ainda que na concentração $0,250 \mathrm{mg} / \mathrm{mL}$ houve crescimento bem reduzido em relação a concentrações mais baixas do óleo essencial de Cymbopogon citratus. 
$\begin{array}{llllllll}1,0 & 0,500 & 0,250 & 0,125 & 0,062 & 0,031 & 0,015 & 0,0078\end{array}(\mathrm{mg} / \mathrm{mL})$

$\because y \bigcirc \bigcirc$ C. albicans.

C. Tropicalis

C. parapsilosis

$\begin{array}{llllllll}1 & 2 & 3 & 4 & 5 & 6 & 7 & 8\end{array}$

(2)

Figura 3. Atividade antifúngica (CFM) do óleo essencial de Cymbopogon citratus cultivado em Maringá - PR na concentração de $1,0 \mathrm{mg} / \mathrm{mL}$ a $0,0078 \mathrm{mg} / \mathrm{mL}$, para as cepas de C. albicans, C. tropicalis e C. parapsilosis.

\section{DISCUSSÃO}

Pode-se observar um alto teor de óleo essencial obtido a partir das folhas de Cymbopogon citratus, sendo o rendimento de ambas as espécies em estudo superiores aos encontrados por Duarte et al ${ }^{7}$, que foram de $0,1 \%$ e 0,33\%, para Lippia alba e Cymbopogon citratus respectivamente.

Quanto à atividade antifúngica dos óleos essenciais para a C. albicans, os dois óleos essenciais, bem como a mistura destes, apresentaram os mesmos valores de concentração de inibição mínima, que foram de $0,125 \mathrm{mg} / \mathrm{mL}$, caracterizando-se que apesar de serem óleos essenciais de espécies diferentes resultaram no mesmo valor de CIM.

Em estudo relatado por Duarte et al ${ }^{7}$, o óleo essencial de Lippia alba causou uma inibição no crescimento de Candida albicans com MIC de $0,600 \mathrm{mg} / \mathrm{mL}$. Segundo Fontenelle et a ${ }^{22}$, ao analisar o óleo essencial de uma outra espécie de Lippia (Lippia sidoides), frente a diferentes cepas de Candida albicans, relataram a concentração inibitória mínima (CIM) nas concentrações de $0,620 \mathrm{mg} / \mathrm{mL}$ e $1,250 \mathrm{mg} / \mathrm{mL}$.

Já em outro trabalho ${ }^{23}$, os resultados com o óleo essencial de uma outra espécie de Cymbopogon (Cymbopogon winterrianus), resultaram na concentração inibitoria mínima (CIM) de $2,250 \mathrm{mg} / \mathrm{mL}$.

A discrepância do CIM se justifica pela utilização de óleos essenciais de diferentes espécies, e as variabilidades das cepas utilizadas. No entanto, os óleos essenciais de Lippia alba e Cymbopogon citratus, bem como a mistura destes em igual volume mostram-se igualmente ativos para a Candidas albicans.

Quanto a Candida tropicalis é visto uma maior atividade do óleo essencial de Cymbopogon citratus, em relação ao óleo essencial de $\mathrm{Li}$ ppia alba, bem como a mistura de ambos óleos.

De acordo com Fontenelle et al ${ }^{22}$, demonstraram atividade antifúngica do óleo essencial de Lippia sidoides, frente a Candida tropicalis, com concentrações inibitória mínima (CIM) de $1,250 \mathrm{mg} / \mathrm{mL}$ e $2,500 \mathrm{mg} / \mathrm{mL}$ para cepas diferentes de candida.

Ao determinar a CIM, do óleo essencial de Cymbopogon winterrianus ${ }^{23}$, verificaram uma ação inibitória na concentração de 0,562 mg/mL para a Candida tropicalis.

Em outro estudo realizado por Santos et al ${ }^{9}$, que utilizou amostras de leveduras isoladas de candidíase vulvovaginal, a concentração inibitória mínima foi de $0,640 \mathrm{mg} / \mathrm{mL}$ para C. albicans e 1,250 mg/mL para C. tropicalis, para o óleo essencial de Cymbopogon citratus. Os maiores valores de CIM encontrados nesse trabalho pode ser justificado, pelas cepas de cândida decorrente de candidíase vulvovaginal e outros fatores que podem influenciar são a técnica extração e às diferenças na composição química da planta, que são determinada por fatores como local, condições de cultivo, época de colheita, tempo de extração do óleo essencial, tempo de armazenamento que podem promover mudanças quantitativas e qualitativas nos constituintes do óleo essencial ${ }^{24}$.

A atividade inibitória para Candida parapsilosis foi também maior para o óleo essencial de Cymbopogon citratus, e pode-se observar que a mistura dos óleos essenciais, não apresentaram maior atividade em relação ao óleo essencial de Cymbopogon citratus, sendo sua atividade muito superior em relação ao óleo essencial de Lippia alba.

Contudo, de acordo com Nascimento et $\mathrm{al}^{6}$, a associação das plantas medicinais e/ou seus subprodutos pode atuar inibindo ou até mesmo 
intensificando o efeito terapêutico dos medicamentos convencionais, bem como interferir na resposta esperada.

A atividade antifúngica foi mais efetiva do óleo de Cymbopogon citratus em relação à Lippia alba, bem como a mistura destes, frente as três cepas testadas.

O efeito antifúngico do óleo essencial de C. citratus, segundo Vargas et $\mathrm{al}^{25}$ é devido a presença majoritária de citral, um terpenóide oxigenado (aldeído) que relataram apresentar acentuada atividade antifúngica frente a cepa de C. albicans.

Segundo Cavalcanti et al ${ }^{23}$, ao analisar o óleo essencial de Cymbopogon winterrianus, frente as espécies de Candida albicans e Candida tropicalis, relatam a concentração fungicida mínima (CFM) nas concentrações de 4,500 mg/mL e $0,562 \mathrm{mg} / \mathrm{mL}$ respectivamente.

No estudo de Vargas et $\mathrm{al}^{25}$, relataram o efeito antifúngico do óleo essencial de C. citratus para cepa de C. albicans a partir da concentração de 1000 mg/mL. A diferença acentuada na concentração antifúngica quando comparada a esta pesquisa, que foi de $0,500 \mathrm{mg} / \mathrm{mL}$, pode ser justificada pela metodologia empregada por Vargas et $\mathrm{al}^{25}$, que utilizaram o método de difusão em ágar para avaliar a atividade antifúngica.

\section{CONCLUSÃO}

Os óleos essenciais de Lippia alba e de Cymbopogon citratus apresentaram atividade fungicida para cepas de Candida sp, sendo que o óleo essencial de Cymbopogon citratus apresentou a melhor atividade. Observou-se que a mistura dos óleos essenciais não potencializou o efeito antifúngico para os microrganismos testados. No entanto, ressalta-se a importância de futuras pesquisas para avaliar possíveis interações entre óleos e consequentemente atividade antifúngica, resultados estes que poderão contribuir para a descoberta de futuros ativos com atividade antimicrobiana.

\section{REFERÊNCIAS}

1. Sampaio LA, Oliveira DR, Kenrtopf MR, Brito Junior FE, Menezes IRA. Percepção dos enfermeiros da estratégia saúde da família sobre o uso da fitoterapia. REME - Rev. Min. Enferm. 2013;17(1):76-84.

2. Santos RL, Guimarães GP, Nobre MSC, Portela AS. Análise sobre a fitoterapia como prática integrativa no Sistema Único de Saúde. Rev. Bras. Pl. Med., Botucatu. 2011;13(4):486-491.

3. Oliveira MMM, Brugnera DF, Cardoso MG, Guimarães LGL, Piccoli RH. Rendimento, composição química e atividade antilisterial de óleos essenciais de espécies de Cymbopogon. Rev Bras. Pl. Méd, Botucatu. 2010;13(1):8-16.

4. Oliveira RAG, Lima EO, Vieira WL, Freire KRL, Trajano VN, Lima IO, et al. Estudo da interferência de óleos essenciais sobre a atividade de alguns antibióticos usados na clínica. Rev. Bras. Farmacog. Brazil. J. Pharmacog. 2006;16(1):77-82.

5. Machado RMA, Mussi-Dias V, Souza CLM, Silva LB, Freire MGM. Avaliação de óleos essenciais sobre o crescimento in vitro do fungo Colletotrichum gloeosporoides. Persp. Online: biol. \& saúde, Campos dos Goytacazes. 2013;8(3):64-75.

6. Nascimento GGF, Locatelli J, Freitas PC, Silva GL. Antibacterial activity of plant extracts and phytochemicals on antibiotic resistant bacteria. Brazil. J. of Microbiol. 2000; $31:(247-56)$.

7. Duarte MCT, Figueira GM, Sartoratto A, RehderVLG, Delamerlina C. Anti-Candida activity of Brazilian medicinal plants. Journal of Ethnopharmacology. 2005;97:305-311.

8. Tavares IB, Momenté VG, Nascimento IR. Lippia alba: estudos químicos, etnofarmacológicos e agronômicos. Pesq. Aplic. \& Agrotecnol. 2011;4(1):204-12.

9. Santos EB, Dantas GS, Santos HB, Diniz MFFM, Sampaio FC. Estudo etnobotânico de plantas medicinais para problemas bucais no município de João Pessoa, Brasil. Rev. Bras. Farmacog. Brazil. J. Pharmacog. 2009; 19(1B):321-24.

10. Aguiar JS, Costa MCCD, Nascimento SC, Sena KXFR. Atividade antimicrobiana de Lippia alba (Mill.) N.E. Brown (Verbenaceae). Revista Brasileira de Farmacognosia. 2008;18(3):436-440.

11. Jannuzzi H, Mattos JKA, Vieira RF, Silva DB, Bizzo HR, Gracindo LAM. Avaliação agronômica e identificação de quimiotipos de erva cidreira no Distrito Federal. Hortic. Bras. Brasília. 2010;28(4):412-417.

12. Barros FMC, Zambarda EO, Heinzmann BM. Variabilidade sazonal e biossíntese de terpenóides presentes no óleo essencial de Lippia alba (Mill.) N. E. Brown (Verbenaceae). Quim. Nova. 2009;4:861-867.

13. Amarante CVT, Ernani PR, Souza AG, Steffens CA. Calagem e adubação fosfatada favorecem o crescimento do capim-limão, Cymbopogon citratus (DC) Stapf. Rev. Bras. Pl. Med., Botucatu, 2012;14(1):92-96.

14. Guimarães LGL, Cardoso MG, Sousa PE, Andrade J, Vieira SS. Atividades antioxidante e fungitóxica do óleo essencial de capim-limão e do citral. Rev. Ciênc. Agron. 2011; 42(2):464-472. 
15. Zardo V, Mezzari A. Os antifúngicos nas infecções por Candida sp. Newslav. 2004;63:136-146.

16. Colombo AL, Guimarães T. Epidemiologia das infecções hematogênicas por Candida spp. Revista da Sociedade Brasileira de Medicina Tropical. 2003;36(5):599-607.

17. Guimarães LGL, Cardoso MG, Zacaroni LM, Lima RK. Influência da luz e da temperatura sobre a oxidação do óleo essencial de capim -Limão, Quím. Nova, 2008;31(6):1476-1480.

18. Silva AKF, Lisboa JES, Barbosa MPCS, Lima AF. Infecções urinárias nosocomiais causadas por fungos do gênero candida. Ciências Biológicas e da Saúde, 2014;2(1):45-57.

19. Ayoade, JO. Introdução à climatologia para os trópicos. 12. ed. Rio de Janeiro, RJ: Bertrand Brasil, 2003.

20. Farmacopéia Brasileira. 2000. 4. ed., Atheneu: São Paulo.

21. National Committee For Clinical Laboratory Standards. 2000. Reference Method For Broth Dilution Antifungal Susceptibility Testing Of Yeast. Approved Standard M27-A. National Committee For Clinical Laboratory Standards, Wayne, Pa. 22. Fontenelle ROS, Morais SM, Brito EHS, Kerntopf MR, Brilhante RSN, Cordeiro RA, et al. Chemical composition toxicological aspects and antifungal activity of essential oil from Lippia sidoides Cham. Journal of Antimicrobial Chemotherapy. 2007;59: 934-940.

23. Cavalcanti YW, Almeida LFD, Padilha WWN. Atividade antifúngica de três óleos essenciais sobre cepas de cândida. Rev Odontol Bras Center. 2011;20(52): 77-82.

24. Santos A, Paduan RH, Gazin ZC, Jacomassi E, D' Oliveira PS, Cortez DAG, et al. Determinação do rendimento e atividade antimicrobiana do óleo essencial de Cymbopogon citratus (DC.) Stapf em função de sazonalidade e consorciamento. Brazilian Journal of Pharmacognosy. 2009;19(2):436-441.

25. Vargas FS, Oliveira CF, Giro EMA, Sacramento LVS, Spolidorio DMP, Costa CAS. Efeito Antimicrobiano e Citotóxico do Óleo Essencial de Cymbopogon citratus sobre células Odontoblastóides. Rev Odontol Bras Central. 2010;19(49):101-117.

Recebido em 18 de dezembro de 2014. Aprovado em 13 de novembro de 2015. 